\title{
Pre-Service Elementary Teachers' Field Experiences in Classrooms Led by Science Specialists
}

\author{
Tina Varma · Deborah L. Hanuscin
}

Published online: 15 July 2008

(C) Springer Science+Business Media, B.V. 2008

\begin{abstract}
The purpose of this study was to examine the experiences of preservice elementary teachers in a content-specific field-based experience with elementary science specialists. Data collected from electronic discussions, interviews, and observations in the field revealed preservice teachers experienced a wide range of instructional and assessment strategies in specialists' classrooms, but failed to generalize aspects of the specialist model of science instruction to traditional models for delivery of science instruction at the elementary level. Implications for supporting preservice teachers' learning to teach science through participation in a field experience with specialists are discussed.
\end{abstract}

\section{Introduction}

Preservice elementary teachers (PETs) enter their methods courses with a vision of themselves as science teachers that is closely related to their experiences as science learners (Abell and Bryan 1997). Many expect to teach science the way they were taught (Kelly 2000), an expectation that can directly oppose reform-oriented perspectives advocated in their teacher education programs. To help PETs develop reform-oriented teaching practices, we must provide them with field experiences that create opportunities to experience this kind of instruction. Providing appropriate field experiences, however, can be challenging in that "the desirable

\footnotetext{
T. Varma

Department of Curriculum \& Instruction, University of Central Missouri,

3330 Lovinger Building, Warrensburg, MO 64093, USA

e-mail: varma@ucmo.edu

D. L. Hanuscin $(\bowtie)$

Department of Learning, Teaching, and Curriculum, University of Missouri,

303 Townsend Hall, Columbia, MO 65211, USA

e-mail: hanuscind@missouri.edu
} 
kinds of classrooms in which students should serve their apprenticeships quite often do not exist" (Abell 2006, p. 77). While 77\% of elementary teachers consider themselves well qualified to teach language arts and reading, fewer than three in ten feel well qualified to teach science (Weiss et al. 2001). Elementary teachers' anxiety and negative attitudes about teaching science have been well documented in previous decades (Westerback 1982; Czerniak and Chiarelott 1990) as well as the tendency to avoid teaching science altogether (Tilgner 1990). Thus, PETs may find themselves in classrooms in which the cooperating teacher focuses on reading and math to the exclusion of science and in which there is no opportunity to experience the implementation of inquiry-based science instruction (van Zee et al. 2003). As a result, such field experiences may actually undermine the efforts of elementary science methods instructors (Abell 2006).

To address anxieties typically associated with the teaching of elementary science and to help them become more confident and competent in their abilities to teach science, Moseley et al. (2004) suggested that content-specific school-based experiences can afford PETs with opportunities to focus on content and instructional strategies at deeper levels. A challenge, however, is that elementary teachers are content generalists and often lack a deep understanding of science. Unlike secondary science teachers, elementary teachers typically do not major in science, and $40 \%$ have taken four or fewer semesters of science coursework (Fulp 2001). Thus, many are not in a position to serve as content experts due to a poor science background.

In recent years, however, many school districts have begun to address the disconnect between how elementary school teachers have been prepared to teach science and the critical need for teachers who have a deeper knowledge of science and effective means for translating that knowledge into forms accessible to elementary learners. A number of strategies have emerged, including training or hiring teachers who can serve as science specialists (Committee on Science and Mathematics Teacher Preparation 2000).

In the U.S., approximately $15 \%$ of elementary students receive instruction from a science specialist in addition to their regular teacher, and another $12 \%$ receive science instruction from a science specialist instead of their regular classroom teacher (Weiss et al. 2001). Abell (1990) described four delivery models for elementary science involving science specialists:

- The Physical Education Teacher Model in which classes visit a science laboratory on a rotating basis, just as classes go to the gymnasium for physical education.

- The Media Center Model in which classes are scheduled in the laboratory once or twice a week while, for the remainder of the days, the lab is open for individual or class use. Within this model, the science specialist works directly with the children for half of his or her time and for the other half serves as a consultant to help teachers plan, prepare, implement, evaluate, and maybe teach science lessons.

- The Departmentalized Model in which one teacher would be designated as the science teacher. According to Abell (1990), this model, like the other two models, has advantages over the generalist model in that it centralizes science instruction in one room and guarantees science time for every student. 
- The School-Within-a-School Model in which the science specialist works with individuals, small groups, and classes at various times of the day in a specially equipped science laboratory. The specialist then collaborates with a team of 3-4 teachers, each with a different subject area specialization, to design activities that integrate language, math, and other subjects' skills with scientific investigations.

A fifth instructional model proposed by Olson (1992), the Middle School Model, requires the use of a team of two teachers (a science specialist and an elementary teacher) to develop interdisciplinary concepts centered on the needs of the students.

With the proliferation of these specialist delivery models for elementary science instruction in the U.S., teacher education programs may be in a position to choose whether to place PETs in specialists' or generalists' classrooms for their field experience. Intuitively, field placements with specialists may seem a better alternative; given that elementary teachers may devote little if any time to science, a field placement with a specialist would ensure PETs are able to observe and participate in elementary science teaching. Furthermore, it would be expected that specialists have greater content knowledge, pedagogical knowledge, and knowledge of curriculum in science than classroom generalists (Schwartz et al. 1999), and thus would provide appropriate models of instruction.

The literature related to field experiences for elementary science, however, focuses exclusively on field placements with generalists. No study, to date, has provided insight into the experiences and opportunities content-specific field placements with science specialists afford preservice elementary teachers. Thus, as an exploratory study, the goal of our research was to more closely examine the fieldbased experiences of PETs in elementary classrooms in which science is taught by specialists. In doing so, we hoped to learn about the ways in which this unique field experience supports learning to teach science. We focused specifically on one district in which elementary science is delivered through a specialist model and in which preservice elementary teachers are placed with the science specialists for their field experience.

\section{Context of the Study}

Providence School District (pseudonym) is a Midwestern district that serves approximately 17,000 students in rural and small-city settings. Providence utilizes specialists to teach science to students in grades 4-5. These are typically teachers with a higher degree of enthusiasm, interest, or expertise in science; however, no specialized degree in science is required for the position. The district presumes the specialists will be better able to develop inquiry-based pedagogical strategies by focusing their efforts on science alone. Specialists typically work within a single school, though some travel to multiple schools. They meet with each 4th- and 5thgrade class twice a week for $50 \mathrm{~min}$, similar to the Physical Education Teacher Model (Abell 1990). However, not all specialists have their own classroom. In these cases, the specialist teaches science in the students' regular classroom or shares a classroom with another teacher (e.g., art). 
Providence School District hosts students from the nearby university who are seeking Baccalaureate degrees in elementary education. PETs are placed in classrooms led by specialists for their science field experience, rather than in K-3 classrooms in which science is taught by the classroom teacher. This decision reflects an assumption within the teacher education program that specialists' classrooms would provide the PETs with a rich experience in inquiry-based instruction and consistent with what they are learning in their elementary science methods course. However, no empirical data has been collected to support or refute this assertion.

\section{Participants}

Participants in the research included 24 undergraduate elementary education majors (juniors) enrolled in an elementary science methods course taught by Deborah L. Hanuscin, the second author. All were white and, with the exception of one, female. The science methods course has a reflective orientation (Abell and Bryan 1997) and utilizes the National Science Education Standards (National Research Council 1996) as a framework to help PETs develop an in-depth understanding of elementary science teaching and learning through firsthand experiences as learners in modeled lessons, as well as the use of video case studies, readings, and discussions. Assignments are intended to elicit PETs' ideas about science teaching, informed by their experience as learners, and provide them with new perspectives on scientific inquiry and the nature of science.

Along with the methods course, all students take part in a 1-credit field experience in elementary science teaching. This is the first extended field experience for students, who previously participated in classrooms as aides or merely observers for short periods of time. Within the science field experience, PETs (placed in pairs) visit the classrooms of science specialists for one class a week over 16 weeks. While PETs do not plan and teach their own lessons, they take on instructional roles by assisting small groups of students within the science investigations planned by the specialists. Specific tasks are left to the discretion of the specialist; however, no time is provided within the field experience for the specialist to meet in advance of the lesson with PETs. Observations in the field revealed that PETs' participation in the lessons most often consisted of circulating around the room assisting students who had questions.

The field experience course consists entirely of these visits to the schools and does not include face-to-face seminars for PETs to discuss and debrief their experiences. Research emphasizes, however, that such discussions and reflections are critical to PETs' ability to integrate theoretical understandings in making sense of school observations (Pryor and Kuhn 2004). To address this need, weekly Blackboard (Blackboard, Inc., http://www.blackboard.com/) asynchronous discussions were used as a venue for PETs to reflect on their experiences with each other and their instructors. This electronic forum provides a venue for articulating, examining, and reconstructing their prior ideas and beliefs about teaching and learning science. Thus, Blackboard afforded a form of "virtual supervision" of the 
field experience, as well as provided the course instructor with an awareness of PETs' experiences in the field to support building connections to the content of the methods course.

\section{Methodology}

Our work adopts the phenomenological perspective, which attempts to understand the meaning of events and interactions from the point of view of participants (Bogdan and Biklen 2003). We acknowledge that the perspectives of the PETs, course instructors, and specialists might differ; yet, we believe that it is by understanding the perspective of the PETs that we can best impact their learning. As Abell and Bryan (1997) emphasized, "Learning to teach science involves clarifying, confronting, and expanding ideas, beliefs, and values about science teaching and learning" (p. 164). Thus, in our study, we considered not only the experience of PETs in a field placement with specialists, but also how these experiences impact their beliefs about teaching and learning science. Specifically we asked

1. How do PETs describe their experiences in classrooms led by science specialists?

2. How do such content-specific experiences in the field impact PETs' beliefs about elementary science teaching and learning?

\section{Sources of Data}

To better understand the context and experiences of the PETs, Tina Varma, the first author, served as a participant observer by attending the elementary science methods course, observing PETs in their field placements, and monitoring electronic discussions. The major data for this study were PETs' weekly postings on Blackboard. Such reflective writings are an important component of phenomenological research, as they help to recapitulate and reflect on the participants' experiences to create a reflective cognitive stance through which meaning can be assigned to events and interactions experienced by people (Van Manen 1990). Each week, PETs were required to post reflections on their experiences in the field, as well as respond to the posts of two other classmates. While the methods instructor (Hanuscin) provided prompts to guide PETs' observations and reflections, the discussion forum was set up so that PETs' posted topics, which were followed by classmates' responses, formed individual discussion threads.

Several secondary data sources were collected to triangulate analysis of the primary data. These included the researcher's (Varma's) notes from observations of the PETs during the science field experience and science methods course, as well as interviews with participants. Varma attended all 30 class sessions of the methods course; however, because PETs were placed at five different elementary schools with five different specialists, observing all field visits was not possible. Thus, she made a total of 20 visits to field sites, such that each pair of PETs was visited at least 3-4 times over the course of the semester. Additionally, follow-up interviews were 
conducted postsemester with a purposeful sample of eight participants. This group included at least one prospective teacher from each field site. The purpose of the interviews, which lasted between 30 and $45 \mathrm{~min}$, was to probe PETs' thinking more deeply regarding their experiences in the field. In this manner, the interviews served as a form of member check, enabling comparison of interview responses to Blackboard posts for validation purposes. Varma conducted the interviews, which were audiotaped and transcribed for analysis.

\section{Analysis of Data}

Data analysis was conducted by Varma, with Hanuscin serving as a peer debriefer, assisting in conducting validity checks and triangulating data sources. Since Hanuscin was instructor of the methods course, analysis was begun at the conclusion of the semester, after grades were posted, to avoid potential conflicts of interest. In the first level of analysis, participants' Blackboard posts were entered into NVivo (version 6.0, QSR International, http://www.qsrinternational.com/) qualitative analysis software. At this level, the unit of analysis was the individual post; however, since within a single post several different ideas may have been raised, multiple codes may have been used to reference each post. For example, a post may have been coded both "student-centered instruction" and "fostering independence." In general, codes remained close to the data, utilizing low inference.

Following the initial round of inductive coding, Hanuscin tested the validity of the Varma's coding schema by independently applying it to a sample of the data (20\% of the total posts). Upon reaching a high degree of alignment between the coding decisions of the first and second authors, analysis proceeded to the next level. In Level 2, the units of analysis were the individual threads resulting from an initial post (i.e., a post and all of its subsequent replies). At this level, initial categories were identified based on redundancy and the intersection of codes. For example, several related codes formed a category "inquiry." This was followed by a third level of analysis, which included examination of the relative frequency of various codes across the entire set of 691 posts, as well as the 31 message threads. At this level, themes that cut across the various threads were identified.

Following the analyses, several steps were taken to ensure the validity of our findings. First, we cross-checked themes against both field notes and interview data, searching both of these data sources for confirmatory and contradictory data. Throughout our comparison, we found participants' postings within Blackboard to be consistent with their comments made in class, as well as elaborated upon in interviews. Our confidence in the trustworthiness of our analysis was further increased when we sent a draft of the findings via email to participants to review as a final member check. No participant reported discrepancies between his or her perspective and our interpretations. Responses from PETs indicated, for example, that the draft was "very close to what [they] experienced in the science classroom." By using these different forms of triangulation (multiple data sources, multiple methods of data collection, and multiple researcher perspectives) we have enhanced the credibility of our interpretations, shared below. 


\section{Findings}

We present findings related to four domains of the field experience on which prospective teachers' Blackboard discussions focused, including (a) the physical environment of the science classroom, (b) the time allotted to science learning within the school day, (c) the pedagogical strategies used to teach science, and (d) assessment of science learning. Given our research questions, in regard to each domain we focus on both the experiences of the PETs in their field placement and the way their experiences either reinforced or challenged their beliefs about teaching and learning science. Within our discussion, representative pieces of data from PETs' discussions in Blackboard are provided to illustrate emerging themes.

\section{A Place for Science Learning}

In the field placement with specialists, unlike a typical field placement with elementary generalists, PETs observed science being taught in a separate classroom facility. The majority of specialists held science classes in rooms dedicated solely to science and located either in the main building or in portable classrooms (trailers) on campus. This key difference between the generalist and specialist delivery models influenced the expectations PETs had for their field experience. Several anticipated these facilities to look like a "laboratory," reflective of secondary classrooms:

When I looked in the science room, it was a lot different than I expected. I think I expected something more lab like; but, instead of lab stations, there were tables for the students to sit at. (S7)

I really had this image in my mind that I would be walking into lab stations, and the kids would be wearing goggles or lab coats. Why I thought this, I don't know. I knew that 5th graders didn't get into all of that type of science yet, but it was something I envisioned when I knew that science was taught in a different room with a different teacher. (S17)

Though it was different from the way in which they experienced science as elementary students, PETs believed the use of separate classroom facilities to be conducive to developing student interest in science. For example, they indicated that the science-specific decorations and resources in the rooms provided a stimulating environment. After her initial visit, one PET commented, "I was extremely impressed by the learning environment ... [The] room 'breathed' science" (S20). Similarly, a PET placed at another school posted, "The room was a GREAT science room, with animals, posters, science magazines, and many other resources" (S15). By using the classroom for science alone, PETs believed student focus on learning science would be enhanced:

What is neat is that all these different objects [in the classroom] have a common theme of science. Therefore, when the students are in this room, they know they are to be focusing their thoughts on science and not thinking about other assignments they have in different subjects. (S8) 
As another shared, "I think that by having the classroom solely devoted to all different aspects of science, it allows the kids to become focused on the subject" (S19).

Not all PETs had the same experience in the field. A number of specialists shared their "science" rooms with other special area instructors, including the art teachers; and two simply traveled to the regular classroom with their science teaching materials. What is interesting to note, however, is that the PETs placed with those specialists nonetheless echoed the beliefs of their peers. The PETs participating in these classrooms believed sharing the science classroom with another subject, such as art, took away from science and perhaps defeated the very purpose of having a science specialist teach science. They indicated that to obtain full attention of the students and to get them interested in science, the classroom should be exclusively devoted to science.

The science classroom is also the art room. It is easy to see this because there are art supplies and art work hanging all over the walls. Had I not observed the science class taking place in this room, I would never had known that science was even taught in this room. I feel that the room does not encourage a love of science; it just doesn't seem to be interactive. (S17)

Indeed, they believed that a multipurpose classroom would detract from the emphasis on science. As one preservice teacher wrote, "The room appears to be so art focused that the students might be distracted during science lesson" (S8).

Reasons for supporting separate facilities for science ranged from concerns about how students might perceive the importance of science in relation to other subjects, as illustrated above, but also extended to consideration of logistical aspects, such as storage and organization of science materials for instruction, as highlighted in the post below:

The science specialist's classroom was also the art classroom, which seems to be a disadvantage because many materials could not be stored. Therefore, additional materials probably aren't used too often, because it would be difficult to transport them and such. It is unfortunate that the school does not have their own science classroom where they can give the students an opportunity to experience as much science as they can and grow to enjoy it. Sharing the classroom with the art classroom might make students feel that science isn't important enough because it doesn't even deserve its own room. (S19)

The experience of seeing science taught outside of the regular classroom by specialists contributed to PETs' belief that such facilities were advantageous in contributing to a greater focus on science and communicating its importance in the curriculum. What is implicit in the discussion, as well, is a belief that science itself is a separate "subject" in school, rather than a discipline that crosses borders with other subjects, such as mathematics and literacy. Noticeably absent in Blackboard discussions was the belief that science can or should be integrated with other subjects. The specialists with whom PETs were placed did not collaborate with the students' regular classroom teachers to promote interdisciplinary connections, nor 
did the regular classroom teachers support the instruction of the specialists with additional science lessons in the classroom. Thus, the field experience did not expose PETs to effective models for implementing the kinds of interdisciplinary instruction emphasized in their science methods course.

\section{Time for Science Learning}

In a field placement with a classroom generalist who teaches science, PETs might observe science taught on a daily basis; however, in this particular field placement, PETs observed the science specialists teaching science only twice a week for 50 min each session. Though PETs believed that the separate science facilities utilized within the specialist model of science instruction supported student learning, it became clear that they believed the time devoted to science within the district's model was insufficient. As one student commented, "Two days a week ... [is] not enough time to teach students science" (S12). The general feeling among PETs was that the limited time was a barrier to both teaching and learning.

They believed the specialists were "stretched too thin" (there is only one specialist per building) and had too little class time to accomplish their instructional goals. In some cases, this constraint was communicated to the PETs by the specialists:

Our specialist mentioned to us last week that she is still way behind. She has at least ten more activities to do before the end of the year. On average, each activity has been taking our students two class periods, if not more. I know the big issue is time with specialists. They do not see the kids enough to do everything they want to accomplish. (S2)

As a result, of these constraints, PETs felt students did not benefit as much as they might have, given more time to engage in extended investigations and discussion and believed "[I]t would be to the children's benefit if they were able to have more of science time to do experiments and other hands-on activities" (S3).

Some were critical of the instructional decisions specialists made about how to use this time, however, and felt that even within the time constraints learning could take place.

When our teacher feels rushed, which she seems to be most days, she will just tell the class the answers, instead of explaining or letting them explore to find the answer. (S4)

The students were only in class for $50 \mathrm{~min}$ and, therefore, had time for one activity. I felt like [the specialist] overextended the activity when she could've shortened it and moved on to a more in-depth discussion. I felt like learning was not taking place. (S21)

Other PETs were more empathetic of the time constraints under which the specialists operated:

I think that the underlying problem is that the teacher does not have a sufficient amount of time to fulfill the requirements and, therefore, does not 
have time for students to actively explore science; rather, she feels obligated to cover as much material as possible and, as a result, she must feed them the answers. (S16)

In this manner, the fault was placed with the district's model, not with the individual teacher.

PETs' view that science is a vital part of the school curriculum was challenged by their observations in the field of the limited time devoted to this subject within the district's specialist model. However, rather than accepting this constraint, they responded by expressing their belief that science should be given the priority of time in the schedule. With increased time allotted to science, they believed the specialists would be more effective. The sense of being rushed that they noted in observing the specialists teach ran counter to the kind of facilitation of student-centered explorations they believed supported student learning best. Thus, while their field experience did not necessarily provide a model for the kind of extended investigations envisioned in the standards and discussed in the methods course, they were nonetheless able to think critically about what they observed occurring in the field and based on their beliefs that science should be an important part of the curriculum.

\section{Reform-Based Pedagogy}

Previous studies of specialist-led delivery models for elementary science have documented that specialists typically have greater content knowledge, pedagogical knowledge, and knowledge of curriculum in science than classroom generalists (Schwartz et al. 1999). While we have no basis for comparing the instruction of generalists and specialists in this study, it is important to note the way in which prospective teachers believed the instruction they observed in specialists' classrooms illustrated aspects of reform-based pedagogy, such as hands-on explorations and inquiry-based instruction. PETs reported students in specialists' classrooms learned through exploration and active discussions:

The kids seem to enjoy their time with her because the class is not extremely structured. She allows the students to investigate and play with the materials in the classroom.

When they started their bubble experiment she let them discover how to blow a bubble. Then they had a great discussion on what things should be kept the same, what things could be changed, and what a fair test was. (S9)

According to PETs, the specialists fostered student independence during investigations, as students were expected to construct their own understanding:

I thought that science class was meaningful today. I really liked how the specialist encouraged the kids to come up with their own answers. And then she wrote them on the overhead so that the whole class could see that their contributions were important. 
One thing I liked about what they did today was that they developed questions and then left while still thinking about what they had seen. She didn't answer their questions; she didn't really "finish" the activity. She's letting them think on what they noticed for a little bit longer, and then they will finish the activity in the next class period. (S1)

[Replying to S1 above] My science specialist also gives brief instructions and then allows the kids to participate and work together as a team to troubleshoot or investigate how to form a complete circuit. The teacher scaffolds the kids during their working period and answers their questions. The kids seem to learn more when they get to actually work to form an understanding. The teacher does not just tell them the correct answer. (S11)

Though often implicit, as in the posts above, several PETs did specifically refer to the specialists" approach as "inquiry":

The thing I like the most about this approach is that it radiates "the nature of science." It exemplifies how science learning occurs in the first place-guided inquiry is a great way for students to begin to get a feel for all that is involved in the scientific process. ( $\mathrm{S} 10)$

While the posts above seem to indicate that the pedagogy observed in specialists' classrooms was consistent with what PETs were learning in their methods course, there were differences in the degree to which PETs explicated features of inquiry-based instruction in the classrooms they observed, as exemplified in the post below:

Now that I have been in the science classroom a few times, I have come to the conclusion that the teacher emphasizes science as a process of inquiry. I have come to that conclusion because she truly does let the students explore and create meaning for what they are learning for themselves. For instance, during a lesson on experimental designs and the importance of fairness when testing, the teacher really made her students dig deep into their own thoughts. She made them identify the problem at the beginning of the lesson (that what she was having them do wasn't fair), explain why it wasn't fair, decide how they could change the activity to make it better, list the variables that could be changed, and create their own "fair" experiments. Throughout that science class, the students were actively involved in the learning process. (S16)

Thus, what becomes clear is that the PETs' reflections on the instruction they observed in the field reflected the degree to which they internalized the essential features of inquiry introduced in the methods course. This is also evident in posts that discussed instances in which PETs believed the specialists were not fostering student independence and learning through inquiry. For example, when specialists provided specific directions to students about what to state in their write-up of the experiment and the findings, some PETs felt that this was detrimental to the growth of the students as it took away their chance to make their own decisions about the investigations: 
When they were filling out the worksheet with the data table, prediction and hypothesis, and questions, she was telling each group what to write. How are they ever going to learn if she is just giving the answer to make sure they get through everything? (S14)

Despite these exceptions, PETs believed the instructional strategies utilized by the specialists, overall, were beneficial for student learning in science. In this manner, they believed they were viewing appropriate models for how to teach science in their own classrooms. Witnessing the instruction occurring in specialists' classrooms challenged the ideas of those whose own elementary science experiences were lacking:

The students worked on creating circuits. I thought it was really interesting how the teacher presented the lesson. The teacher assigned each student to a certain type of circuit and told them what materials they would need. Other than that, the teacher didn't provide any more information. This was different for me because I grew up in science classes where the teacher walked me through step by step—not much independent thinking was required. Not giving the students all of the information forced the students to think on their own, which allowed them to get more out of the lesson. (S2)

[Replying to S2 above] My science specialist also gives instructions and allows the kids to participate and work together as a team to troubleshoot or investigate how to form a complete circuit. The teacher scaffolds the kids during the working period and answers their questions. The kids seem to learn more when they actually work to form an understanding. The teacher does not just tell them the correct answer. They have to investigate and explore solutions, and then the teacher will demonstrate the correct way to form a circuit. Wow! Our teacher's methods are a lot more beneficial than the direct lectures that I had to sit through day after day. (S4)

Thus, while for some students their observations in specialists' classrooms were simply a reinforcement of their prior beliefs in the importance of hands-on instruction and inquiry, for others this was a challenge to their support of the traditional manner in which they were taught as elementary students. Observing the impact of the instructional strategies on students' learning provided convincing evidence that the specialists' pedagogy was a better alternative to the way in which they were taught. This was consistent with their experiences in the science methods course, where they participated (as learners) in lessons modeled by the professor:

Before this semester, I would have said that allowing the students to experiment on their own would have caused too much chaos and would not have been beneficial to the students. However, activities we have used in class and what I have learned in the field have caused me to change my mind. (S15)

[Replying to S15 above] I agree that structured chaos is a very hard concept to grasp; however, as this semester progresses, I am realizing that students learn much more from exploring and from group involvement. In our science class, we are given a chance every class period to explore, make noise, and confer 
with others. I think if [the professor] was only lecturing, I would not be learning as much. (S21)

In this manner, preservice teacher's concerns about managing hands-on instruction (i.e., a class erupting into chaos) were allayed by the realization that learning could occur in such an environment where students were actively engaged in exploring materials on their own.

\section{Assessment of Science Learning}

Specialists in Providence work together as teams to develop common assessments that are administered to all students in the district. Thus, regardless of the specialist with whom PETs were placed, they had the opportunity to discuss and compare in their Blackboard forums the implementation of similar assessments. The two main assessment strategies discussed by the PETs included science notebooks and tests. Unlike instructional strategies, which were overwhelmingly commented upon favorably by the PETs, the assessment strategies utilized by specialists drew equal praise and criticism.

\section{Science Notebooking}

Analysis of the comments of PETs posted in Blackboard and observations in the field revealed critical differences in the specialists' use of notebooks and tests within each of the classrooms. However, given that PETs observed only one class session a week for 16 weeks with the specialists, their comments must be interpreted with this in mind. The limited number of observations provides an incomplete picture of the specialists' use of assessment over the long term. Nonetheless, these provide important insights regarding PETs' learning during the field experience.

In the methods course, PETs utilized Science Notebooks: Writing About Inquiry (Campbell and Fulton 2003) as a supplementary text. The field experience provided an opportunity to witness implementation of notebooks firsthand. PETs recognized the specialists' use of notebooks as a tool to help students keep track of their investigations.

Today, the students were starting an experiment on how high different balls bounce, and what affects the height. They wrote out the beginning of the lab report in their science notebooks. The science notebooks, in my opinion, are an excellent way for the students to stay organized in science. The notebooks stay in the science classroom, which I also found beneficial so the students would not lose them. At the top of each page, the students had to write the date and time of the lab, and there is also a glossary at the beginning of the notebook. (S12)

However, due to the limited number of visits made by PETs over the semester, it was not clear to them how notebooks served as tools for the teacher to assess students' understanding of science: “To assess students, she also uses their science notebooks. She has the students write all of the class notes, activities, and small reflections. I think she bases part of her grades off of how complete the notebook is" (S1). 
Most PETs felt that too much time was spent organizing and keeping the science notebooks, especially since there was not much time allotted to each science period. They felt that the worksheets could just as easily been kept in a folder. As such, they questioned the value of the notebooks, particularly when they were implemented in teacher-centered ways (i.e., when decisions about what to include in the notebooks and how to organize them were made by the teacher, rather than the students).

I think that it was very distracting for all students in general. Those who had everything glued in and completed were constantly having to give their notebooks to other people so they could copy down graphs and worksheets. (S18)

[Replying to S18 above] I am questioning the value of the science notebooks. I have noticed that some students spend too much time neatly applying glue to their worksheets and carefully putting them in their notebooks. They often do this while the teacher is talking, so they miss what they say. (S8)

Thus, the field experience did not fully support PETs in realizing the value and potential of science notebooks as a teaching and learning tool. The time constraints in which specialists worked, as well as the limited opportunities to observe the use of notebooks long term and discuss this strategy with the specialists contributed to the belief among some PETs that notebooks were a "waste of time."

\section{Summative Assessment: Tests}

In addition to the notebooks, which were primarily used for formative assessment purposes, specialists utilized tests for summative assessment of student learning. Tests were developed for each instructional unit by the district's team of specialists. PETs believed that specialists were using tests appropriately to evaluate student understanding, rather than memorization of facts. As one preservice teacher explained, "I like that the test includes higher order thinking, requiring students to explain their answers and really show that they understand what they are learning" (S13).

While most PETs liked this assessment strategy because they felt that this reinforced learning, they noted discrepancies between their experiences in the field. Discussions in Blackboard reflected very different practices in different specialists' classrooms with regard to helping students prepare for tests, as is evident in the two posts below:

It was a test day for the fifth grade, so we didn't get to see too much instruction. She did, however, run through a study guide before they began. I can see how this would be helpful, but I think it also cuts down on the level of "true" assessment. Maybe everyone in her class will get 100\%, but perhaps that is because they were given many of the answers just a few minutes before they started working on their tests.... I would be interested to see her students' grade cards. (S4)

As the students entered the room, they were informed that they would be getting a study guide today to help prepare them for a test about electricity next Wednesday. 
The students were instructed to work in groups using any materials that they would like to answer the study-guide questions. As I walked around the classroom to assist the students, I was really surprised to find most of the students on task and working well together. The science specialist was also walking around and providing assistance. One thing that was interesting was that any time one or two groups had the same question she would then discuss it with the class so that she was sure everyone was understanding. (S6)

Similarly, some specialists were observed providing assistance to students as they completed the tests. As two PETs placed with the same specialist shared:

Once they thought they were done, she would look over the test and basically tell them if anything was wrong so they could fix it. (S13)

During the test, I feel that she asked too many leading questions when working with students. As a last resort, she would even ask, "Don't you think it makes sense that would be the answer?" (S24)

The majority of PETs (both those who observed specialists giving assistance during testing, as described above, and those who read about it in the posts of their peers) felt that this form of "help" should not be provided during tests, because tests are intended to evaluate student learning, as well as the effectiveness of teaching strategies. They believed that the extra assistance provided by the specialists invalidated the tests. Several PETs responded to the posts above, voicing their concern about the validity of the assessment:

To me, it sounds like the teacher is giving the students too much direction in their own thinking. She seems to be giving them the answers, rather than them trying to find the answers on their own. (S6)

I do not feel that she is helping her students or seeing what they have learned by giving them so much help. I thought a test was to see how much they retained on their own.

I think that by answering every question with the correct answer, the teacher has gone too far. She is not teaching the students to be independent or investigative. How can she consider this a valid form of assessment if she answered all of the questions? (S21)

In these cases, PETs considered the impact of teachers' providing assistance to students during tests on student learning and offered up their own beliefs about assessment in defense of their critiques. Many believed that assistance did not encourage learning and, instead, made students reliant on the teacher. This conflicted with the value they placed on teachers' fostering independence in students as learners:

I also have observed my teacher basically giving the students answers to test questions. She would tell them things like, "Oh, maybe you should chose a different answer, like A." Then she would say, "Don't you think this is correct?" Of course the student will agree! It is more important for a student to understand why that answer is correct.... A teacher is not teaching a student 
anything by providing them with correct answers. She would be teaching them more by allowing them to get it wrong and figure out why it is wrong. (S7)

[Replying to S7 above] Sometimes I think that teachers can give their students too much help. It is good that she is willing to help them with their tests, but it seems that she is not letting them think on their own. This could be a problem for some students because they will never have to struggle to find an answer. If they have trouble with a question, they know they don't have to try because the teacher will help them. (S9)

Given their beliefs about assessment, the students placed in classrooms in which specialists provided "assistance" during tests experienced an ethical dilemma. Because they felt conflicted about the nature and amount of assistance provided to students by the specialists, PETs in classrooms where this occurred were confused about their role in the classroom during tests.

We weren't sure how much guidance we were to give the students if they were stuck on the problems. (S22)

I was really surprised at the teacher during the testing time ... . The students asked many questions. She would prompt them to help them get the answer, but the way she would prompt them, she was almost giving them the answer. I tried to answer a [student's] question, and she did not like the way I was prompting the student and "showed" me what I should be doing instead. I do not feel she is helping her students or seeing what they have really learned by giving them so much help. I thought a test was to see how much they retained on their own. (S8)

Drawing on their own understanding of the purposes of assessment, PETs interpreted the students' need to ask questions during the tests as a sign that they were not ready to be evaluated and that further instruction and remediation was necessary.

Many of the test questions were based on the activities they did in class. She would refer back to the activity and discuss it with them, pretty much just telling them what happened. If I were the teacher I would tell them to think about the activity we did in class that was similar and not just remind them of every aspect that happened in the activity, telling them what each part was and how to use it. How is she assessing if she is just telling them what they did and they write that on the test? They don't know what they are being tested on and should not be taking a test if they are not ready. (S23)

The discussions in Blackboard surrounding assessment thus highlighted broader questions of when it is appropriate to assess students (summatively).

\section{Discussion}

Field experiences are recognized by both researchers and prospective teachers as playing a vital role in teacher education programs by allowing student teachers to 
bridge the gap between theory and classroom practice (Krustchinsky and Moore 1981) and socializing prospective teachers for their roles in the classroom (Dueck et al. 1984). We operated under the assumption that experiences afforded by placements with science specialists might differ in critical ways from more traditional field experiences in which PETs are placed with classroom generalists. Through this exploratory study, we sought to characterize and understand the experiences of PETs in science field experiences in classrooms led by specialists. Our intent was to provide insight into ways to enhance the effectiveness of the field experience through examination of students' experiences in relation to their learning in the methods course.

Our first research question focused on characterizing PETs' experiences in their field placements with specialists. Data indicate the specialists' classrooms, in general, provided examples of visually stimulating and resource-rich science environments, which can be considered a positive aspect of the field placement. Discussion in Blackboard revealed that, for the most part, PETs felt that the field experience provided them with an appropriate model of elementary science teaching that was consistent with the focus of their science methods course. However, that PETs believed science should be conducted in separate facilities raises concern. Given that they are being prepared as generalists, rather than specialists, it is not clear how well this experience enabled them to envision how to create a stimulating and resource-rich environment for science in a classroom in which all subjects are taught, nor how to integrate science with other disciplines, such as math and literacy. None of the PETs initiated comments in Blackboard as to the applicability of what they observed in these facilities to ways they might (as generalists) arrange and organize their own classrooms to support science learning.

An additional characteristic of the experience of this field placement that differs from a placement with a generalist relates to scheduling-namely that science "classes" that PETs participated in were confined to 50-min sessions twice weekly. PETs did not have an opportunity to observe science as a part of daily instruction in elementary classrooms. While this could be viewed as a drawback, the fact that students recognized this amount of time was insufficient to accomplish teaching and learning goals can be considered a positive learning outcome and reflective of their understanding of the importance of providing students with time to engage in extended investigations and discussions as emphasized in the standards. Indeed, their participation in this field experience with specialists made salient the issue of student opportunity to learn and the impact of the time available for teachers to teach science an opportunity to learn. Blackboard discussion forums enabled students to explore the complexity of this issue through comparison of their experiences across different specialists' classrooms.

Within the different specialists' classrooms, PETs experienced a diversity of science teaching and assessment strategies-which they might not have experienced if placed in a classroom with a generalist who did not emphasize science. Furthermore, they were able to witness the impact of these strategies on student learning. In some cases, they believed the use of instruction and assessment strategies by specialists did not fully benefit students. Our study thus alerts us to the fact that, while a field placement with specialists guarantees the opportunity for 
PETs to observe and participate in elementary science instruction, it does not necessarily offer a guarantee that the instruction in the specialist's classroom will be an ideal model of reform-based practice. However, this kind of experience could also be expected in a field placement in which science is taught by generalists. As Abell (2006) emphasized, it is difficult to identify placements for field experiences in which the teacher's practice is consistent with reform-based pedagogy.

Our second research question was concerned with the degree to which the field experience with elementary science specialists supported or challenged participants' beliefs about elementary science teaching and learning. Many prospective teachers have experienced years of passive, lecture-driven science during their own education and have formed expectations to teach in similar ways (Kelly 2000). According to Abell and Bryan (1997), "Learning to teach science involves clarifying, confronting, and expanding ideas, beliefs, and values about science teaching and learning" (p. 164). As Ebenezer et al. (2003) emphasized, "PETs need to be provided learning situations and experiences that encourage them to articulate, examine, and reconstruct their prior ideas about teaching and learning" (p. 398). Our analyses indicate the field experience with elementary science specialists did, indeed, provide PETs with these kinds of learning opportunities-both in cases where their observations differed from their own experiences as learners and in which the instruction they observed differed from their views of reform-based pedagogy developed in the methods course.

PETs' discussions in Blackboard provide evidence of changes that resulted from witnessing science instruction that differed from what they experienced as elementary learners. Several PETs' prior expectations and beliefs about elementary learners' capacity for independent investigation were challenged, and they ended the semester with higher expectations for their own future students as a result. Additionally, their ideas about the importance of hands-on instruction were supported - and expanded — through their observations of student explorations. This was further encouraged by the opportunity to experience this kind of reform-based instruction, as learners, in their elementary science methods course.

Furthermore, PETs' experiences in the field prompted them to apply their beliefs as critical lenses in regard to what they observed (or read about in others' posts via Blackboard), especially concerning assessment practices utilized by the specialists. Prospective teachers questioned whether students were ready for summative assessments and whether the support given to them during tests and quizzes was appropriate. Through reflecting on these experiences, PETs' values (e.g., fostering student independence as science learners, encouraging students to construct their own meaning) became an explicit part of the discussion. The criticisms they made about the practice of specialists, supported by their own beliefs and knowledge, can be viewed as a commitment to their values. In this manner, what some might consider a negative experience actually served to strengthen PETs' resolve to teach in line with recommendations in the standards. As Ebenezer et al. (2003) stated, such that collaboration and exchange with others in online communities can enhance teacher reflection by "generating and unfolding ideas in multiple perspectives and solutions that contribute to better and mutual understanding" (p. 309). 


\section{Implications}

No field experience is without problems. Abell (2006) identified three main challenges to the elementary science field experience. These include (a) logistical and institutional challenges, (b) supervision challenges, and (c) challenges to teacher learning. We found the logistical and institutional challenges of arranging a field experience with elementary science specialists no more difficult than arranging and coordinating a more traditional field experience with elementary generalists. Similarly, the supervision challenges of ensuring that PETs are provided with support and feedback during their field experience were just as easily managed via Blackboard as they would have been if PETs were in generalists' classrooms. Though, as previously stated, students were placed with specialists at multiple school sites, and the same would have been true in our case had field placements been made with generalists.

Although we do not have a comparison group (preservice elementary teachers are assigned only to classrooms led by specialists for science), we believe that a field placement with specialists may have one significant advantage over more traditional field placements with generalists in regard to teacher education. Whereas there is a likelihood that science may not be taught in generalists' classrooms (e.g., Tilgner 1990), the field placement with specialists offers a guarantee that PETs will be able to observe and participate in the teaching of science to elementary children. Our prior experience as teacher educators has alerted us to the likelihood that prospective teachers may be placed in classrooms where science is not taught and the difficulties that this poses in supporting their learning in the science methods course. In a pragmatic sense, we argue that seeing any science teaching is preferable to seeing no science teaching during a field experience. Yet, it must also be acknowledged that a field placement with specialists, at least in our context, provides no greater guarantee that PETs would experience reform-based pedagogy that aligned with their learning in the methods course. We would argue, however, that as Abell (2006) emphasized, such "ideal" classrooms are rare. What is important in cases in which field classrooms do not support the pedagogy advanced in the methods course is that PETs are able to apply their knowledge and understandings about elementary science teaching to make sense of these situations. We feel the PETs in our study were able to do so in constructive ways. Indeed, the Blackboard discussions provided an appropriate forum for reflecting on these experiences and exploring the underlying pedagogical issues.

One disadvantage of field placements with specialists in regard to teacher learning is the context-specific nature of the specialist model. Specialist-led science programs, while more common over the past several decades, are not the norm. It is, therefore, unlikely that the PETs in our study will obtain teaching positions as elementary science specialists. Indeed, the methods course, as well as the teacher education program, is intended to prepare them as generalists. Several instances in the data raise questions about the degree to which PETs' learning through this experience transfers to their understanding of teaching science within a generalist model. For example, prospective teachers supported the use of separate facilities for science instruction. Implicit within their discussions is the belief that science should 
be taught and learned separately from other disciplines. Thus, a content-specific field placement with specialists, arguably, does not provide PETs with a model for managing and organizing science materials within a traditional (generalist) delivery model nor integrating science instruction with the teaching of other disciplines. This is of particular interest to elementary science teacher educators, given that helping teachers see, understand, and implement instructional practices that rely on the teachers' strengths in language arts instruction to improve their teaching of science content could be a solution to the lack of confidence in science instruction (Dickinson and Young 1998).

One implication of this research for the design and structure of the methods course is that PETs be provided with additional support in identifying ways to apply the strategies employed within the specialist model to the regular classroom, as well as to utilize strategies not observed within this particular delivery model (e.g., linking of science with literacy and numeracy). As Jones and Edmunds (2006) emphasized, teacher education programs should be structured to prepare PETs with information about the different delivery models of science instruction they may encounter. Future elementary teachers need to be able to collaborate with resource teachers, special science instructors, or teach science in a self-contained classroom setting.

As an exploratory study, this research has both answered our questions and raised new ones. For example, while it is clear that the PETs embraced the pedagogy of the specialists, it remains to be seen in what ways PETs' future practices are influenced by their experiences in the field. Specifically, the degree to which learning from the specialist model is transferable to teaching in a generalist model is unknown. We argue that teacher education program evaluations must take into account such questions in determining the appropriateness of field placements for elementary science. Our study suggests that there are both advantages and drawbacks that must be considered to effectively support learning to teach science.

\section{Appendix: Field Discussion Prompts Provided to Students}

The following are suggested to focus your observations of science teaching in your field placement and guide your discussion in Blackboard. You should log in each week to share your own experiences in the field, as well as respond to the posts of your classmates.

- In class, we discuss the use of specialists to teach science. From your conversations with the specialists and your observations of both the regular classroom setting and sessions for science, what do you see as the advantages/ disadvantages of this model?

- You analyzed your prior science learning experiences by writing a science autobiography. How does the science instruction you observe in your field placement compare to your own experiences?

- How do specialists address the state and national standards in their lessons? How do they determine whether students have met these standards? 
- You have been introduced to a number of questioning strategies in the methods course. How would you characterize the questioning strategies used by the specialist you observe?

- You have been introduced to a number of common misconceptions elementary learners hold about science. Do the students with whom you are working have misconceptions you can identify? How do you know?

- You are learning about different assessment strategies for identifying students' prior knowledge, measuring student learning, and evaluating instruction. Describe an assessment used by the specialist you observe. What was the purpose of this assessment? What information was gained through this strategy? How was this information used to improve teaching/learning?

- In class, we have explored the use of science notebooks. How are notebooks utilized in the science classroom you observe?

- This semester we have focused on inquiry-based instruction. In what types of inquiry do the students in the classroom you observe engage? What is the specialist's role during inquiry? What is the students' role?

- We use the nature of science as a framework for teaching and learning science in the methods course. How is the nature of science reflected in the lesson you observe? How is the nature of science being conveyed to students?

- We have discussed the challenges of managing science instruction in the methods course. What classroom management and materials management strategies have you observed in the field?

- You have been introduced to several ways to assist students with special needs in being successful in the science classroom. How do the diverse students in your classroom receive support from the specialist? From other professionals?

\section{References}

Abell, S. K. (1990). A case for the elementary science specialist. School Science and Mathematics, 90, 291-301.

Abell, S. K. (2006). Challenges and opportunities for field experiences in elementary science teacher preparation. In K. Appleton (Ed.), Elementary science teacher education: International perspectives on contemporary issues and practice (pp. 7-89). Mahwah: Erlbaum.

Abell, S. K., \& Bryan, L. (1997). Reconceptualizing the elementary science methods courses using a reflection orientation. Journal of Science Teacher Education, 8, 153-166.

Bogdan, R. C., \& Biklen, S. K. (2003). Qualitative research for education. An introduction to theories and methods (pp. 22-27)). Boston: Allyn and Bacon.

Campbell, B., \& Fulton, L. (2003). Science notebooks: Writing about inquiry. Portsmouth: Heinemann.

Committee on Science and Mathematics Teacher Preparation. (2000). Educating teachers of science, mathematics, and technology: Practices for the new millennia. Washington, DC: National Academy Press.

Czerniak, C., \& Chiarelott, L. (1990). Teacher education for effective science instruction-a social cognitive perspective. Journal of Teacher Education, 41(1), 49-58.

Dickinson, V. L., \& Young, T. A. (1998). Elementary science and language arts: Should we blur the boundaries? School Science and Mathematics, 98, 334-340.

Dueck, K., Altmann, H., Haslett, K., \& Latimer, J. (1984). Early exploratory field experiences in teacher preparation programs. Education Canada, 24, 34-38.

Ebenezer, J. V., Lugo, F., Beirnacka, B., \& Puvirajah, A. (2003). Community building through electronic discussion boards: Preservice teachers' reflective dialogues on science teaching. Journal of Science Education and Technology, 12, 397-411. 
Fulp, S. (2001). The status of elementary science teaching: A report of the 2000 National Survey of Mathematics and Science Education. Chapel Hill: Horizon Research.

Jones, M. G., \& Edmunds, J. (2006). Models of elementary science instruction: Roles of science specialists. In K. Appleton (Ed.), Elementary science teacher education: International perspectives on contemporary issues and practice (pp. 317-344). Mahwah: Erlbaum.

Kelly, J. (2000). Rethinking the elementary science methods course: A case for content, pedagogy, and informal science education. International Journal of Science Education, 22, 755-777.

Krustchinsky, R., \& Moore, B. (1981). Early field experiences: A vital part in the training of elementary teachers. Kappa Delta Pi Record, 17(4), 119-120.

Moseley, C., Ramsey, S. J., \& Ruff, K. (2004). Science buddies: An authentic context for developing preservice teachers' understandings of learning, teaching, and scientific inquiry. Journal of Elementary Science Education, 16(2), 1-18.

National Research Council. (1996). National science education standards. Washington, DC: National Academy Press.

Olson, A. K. (1992). In praise of the classroom teacher. Science and Children, 29(1), 16-17.

Pryor, C., \& Kuhn, J. (2004). Do you see what I see? Bringing field experience observations into methods courses. The Teacher Educator, 39, 249-266.

Schwartz, R. S., Abd-El-Khalick, F., \& Lederman, N. G. (1999, April). An explanatory study of the "effectiveness" of elementary science specialists. Paper presented at the Annual Meeting of the Association for the Education of Teachers in Science, Austin, TX.

Tilgner, P. J. (1990). Avoiding science in the elementary schools. Science Education, 74, 421-424.

Van Manen, M. (1990). Researching lived experience: Human science for an action sensitive pedagogy. New York: State University of New York Press.

van Zee, E., Lay, D., \& Roberts, D. (2003). Fostering collaborative inquiries by prospective and practicing elementary and middle school teachers. Science Teacher Education, 87, 588-603.

Weiss, I. R., Banilower, E. R., McMahon, K. C., \& Smith, P. S. (2001). Report of the 2000 National Survey of Science and Mathematics Education. Chapel Hill: Horizon Research.

Westerback, M. E. (1982). Studies on attitude toward teaching science and anxiety about teaching science in preservice elementary teachers. Journal of Research in Science Teaching, 19, 603-616. 